\title{
FEATURE: A GENOLOGICAL DRAFT
}

\section{Natalia Kowalska-Elkader}

Department of Journalism and Social Communication,

Faculty of Philology, University of Lodz, Poland

\begin{abstract}
The genre which is the basis of my research and the subject of analysis in this text is the feature, also called artistic radio documentary. The main aim of the article is to show the variety of features and the possible way to define and understand this genre. The first section describes the origins of this type of program and how it can be defined by European, Australian and American researchers. It also provides the genre pattern of feature divided into four aspects. Later in the text I describe subgenres of contemporary feature based on their structure and used sound materials. The second part of the text focuses on representations of these categories in Polish and foreign productions and tries to classify them according to the type of fiction applied or its form. The employed methods include literary analysis and criticism as well as some elements of structural analysis. The research questions I ask myself are related to the way of creating features, their form and its relation to the content.
\end{abstract}

Keywords: feature, radio documentary, radio art, narration, radio genres

\begin{abstract}
About the author: Natalia Kowalska-Elkader, Ph.D. is a radio researcher at the University of Lodz, Poland. Her research is focused on artistic radio and sound art. She is interested in the experimental form of audio art. She has published essays exploring feature genre and its subgenres. Author of two books about the radio feature Forma i treść. Polski i zagraniczny feature radiowy oraz jego odmiany gatunkowe (Łódź 2019) and about the experimental radio stories Historie eksperymentalne. Szkice o gatunkach radia artystycznego (Lódź 2020). Member of the European Communication Research and Education Association (Radio and Sound Section).
\end{abstract}

Copyright (C) 2021 Natalia Kowalska-Elkader

Article history: Received: 3 November 2020; Reviewed: 5 February 2021; Revised: 18 March 2021; Accepted: 21 March 2021; Published: 19 April 2021

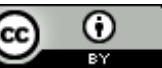

This open access article is published and distributed under a Creative Commons Attribution 4.0 International License.

Citation (APA): Kowalska-Elkader, N. (2021). Feature: A genological draft. Studies in Linguistics, Culture, and FLT, 9(1), 7-20. doi: 10.46687/SILC.2021.v09i01.001. 
The genre which is the basis of my research and the subject of analysis in this text is the feature. The first section describes the origins of this type of program and how it can be defined, and then the text focuses on representations of this category in Polish and foreign productions, and tries to classify it according to the type of fiction applied.

The essence of the feature is the synthesis of the documentary truth, the perspective of the author and their creative expression. Reality becomes the starting point for creating an artistic program whose form and content are inseparably connected. Melchior Wańkowicz's statement seems to be adequate in this context: "Only when I get the fact [...] it grows, flourishes in synthesis, comparisons, analogies. Fact is a catalyst for my imagination" (Kąkolewski, 1987, p. 9). Facts can trigger the imagination and give the material to create the story. Artistic segments created by the author are not less important or disturbing documentary messages, they are an inherent part of the feature and they can also convey the truth. Wańkowicz distinguished essential and documentary truth: "essential truth, although different from the documentary truth, is not the truth of second quality" (Kąkolewski, 1987, p. 9). The concept of "essential truth" as I understand it is telling a story that will reflect its essence, emotions and atmosphere, not necessarily with the use of a documentary, authentic recordings or cited facts. The feature's resources are infinite, limited only by the imagination of the creator, therefore the key to this genre are such formal audio solutions and the use of all necessary phonic materials that will guarantee the creation of a work of high artistic value while fully presenting the subject discussed.

Feature radio programs derive from both aforementioned forms of radio, allowing free intermingling of them and making full use of the possibilities of radio broadcasting; moving away from extreme mimicry and transferring artistic aspects to the relationship with reality, allowing the use of such elements as: performances, radio drama scenes, music, original montage work or the creation of programs in particular conventions. The centre of gravity is shifted to the aesthetic function of the work. Representations of the genre on radio stations in Western Europe, the United States and Australia often contain fictional elements, and have been enriched artistically. Today all over the world these works are called features, the English term cemented in Germany, South Korea and in Polish research. Among Polish radio producers, like in the early fifties in Germany (Fisher, 1964), not everyone uses the term feature and it is often replaced by artistic radio documentary.

\section{Definitions of the genre: western and Polish perspective}

The feature allows you to take full advantage of what radio transmission provides. This means that the resources are endless, and stories can be told in 
many ways. In Western Europe, the United States or in Australia, the feature is an extremely popular form, evidenced by, amongst other things, the fact that for 42 years an International Feature Conference has been organized, the buoyant activity of the American Third Coast Festival, the hundreds of submissions to the PocketDocs competition organized by Radio National in Australia, or the long-term tradition of creating this type of work in the BBC. As Kinga Klimczak (2011), a researcher of documentaries, writes, in the West "the radio documentary existed immediately as a kind of artistic program for the selected". From the beginning, in addition to the production of the purely documentary, artistic programs were created. In Poland, Klimczak explains, the situation presented itself differently. Radio documentaries arose "from social need, as a document showing the current needs of the people". The term feature has been used in German and English-speaking environments since the beginning of research into the art of radio. In Poland, it is the subject of academic research, and a topic of discussion among practitioners. As Klimczak (2011, p. 70) writes, a feature is what "in documentaries is the most artistic, valuable and elite".

In the Polish understanding of the genre, it is a radio documentary enriched with creative elements, fiction, and different from the social documentary which transmits the truth, tells the true story. This distinction also operates in Western Europe, however, it is not as categorical: "the term feature is often used as a synonym for radio documentary, but there is a certain difference. Although the feature is produced in a similar manner to a documentary, it has a wider range and a larger variety of themes" (Chatterjee, n.d.). This range is associated with several possibilities for narrative, methods of montage and other artistic processes. The difference between these two forms of radio expression are also described by the radio expert Sean Street $(2012$, p. 4), who argues that the word documentary suggests the journalistic origin of the genre, and is not derived from the "impressionist world of sound, which rather plays with the facts rather than describes them". The feature, in Street's view, documents the journey of its creator, and not necessarily reality and facts.

One of the first studies of the genre was conducted by Alfred Andersch, a German writer, author of radio plays, and radio journalist. Discussing works on the borderline of drama and documentary, he wrote:

The term feature never refers to the content of the object; rather it describes the way it is presented: from the making, the form, the appearance via the facial aspect of a human, and from fashion to the special inducement of newspapers and radio. Thus, the feature represents the form, and not the object in itself, whereby, however, as in the appearance of a man, sometimes the form and content are the same (Andersch, 1953, p. 95)

Andersch therefore suggests implementing this type of audio work with parallel characteristics to feature broadcasts. The emphasis on form ensures that 
exemplifications of the genre provide listeners with an aesthetic experience, and that the program requires engagement in the role that the form plays. The artistic values of the works are as important as the objects themselves.

In connection with the number of possibilities and formal solutions, the feature is an internally diverse genre; the form of another genre may be chosen or derived from, it "can cover all possible types of radio transmission. It can possess elements of reports, documentaries, descriptions of social, psychological and political issues. It is a form, an art, its resources are unlimited. It ranges from journalism to poetry, from the rational description to the surreal dream" (Andersch, 1953, p. 95).

The difficulties in defining the genre are described in the introduction to $B B C$ Features by the author of the publication, Laurence Gilliam (1950, p. 9), who says that the term feature is also used by filmmakers, and for newspaper journalists it means "everything the editor chooses to print beyond the news and comments". In relation to radio programmes, Gilliam defines the feature as "programs, usually documentaries, realized by using different techniques, usually with the use of dramatization and subject to realist montage". Moreover, the feature should be "an expression of the state of mind of its creator, regardless of the techniques used". The aim of this type of program should be to both inform listeners and provide them with entertainment (Gilliam, 1950, p. 9).

The contemporary German documentary maker and radio producer Jens Jarisch, defines the feature as "an audial creation allowing one to re-experience events and the relationships between them" (Jarisch, online). For Jarisch, the essence of the genre is its duality, where the content is documentary, but the form is artistic. From a broader perspective, a feature may therefore consist of everything that is audible, as well as silence (ibid.). This is in accordance with the statement of Andersch that the resources of the feature are unrestricted. With the possibilities of using artistic means, the number of possible subjects also increases. The feature, as Andersch wrote, may refer to almost any problem.

The perception of feature, especially in Poland, often places it between radio documentary and radio drama. This perspective can be called linear: from documentary radio reportage through partially imaginary feature to fictional radio drama. In my opinion, feature's possibilities and resources are bigger than this and what is more, linear thinking is limited. I would like to suggest nonlinear understanding of feature and other artistic radio genres in general. 


\section{Table 1.}

Linear understanding of feature among artistic radio genres.

Own elaboration.

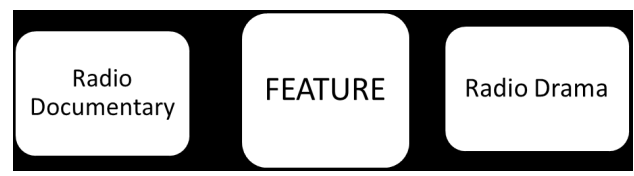

The planetary, non-linear arrangement presented below places feature in the centre of the system to show that all of these kinds of realisations can affect each other and the radio producers can be inspired by all of the forms. Planetary thinking places feature among radio documentary, radio drama and radio experiment. Experimental audio forms are important in general radio analysis. Radio producers often use different narrations and montage tools; stories are interesting due to plot and form. Planetary system shows the variety of feature programs. What is also important is the fact that it can be developed. It is not possible to include every artistic radio form with its varieties in the one graph.

\section{Table 2.}

Planetary understanding of artistic radio genres.

Own elaboration.

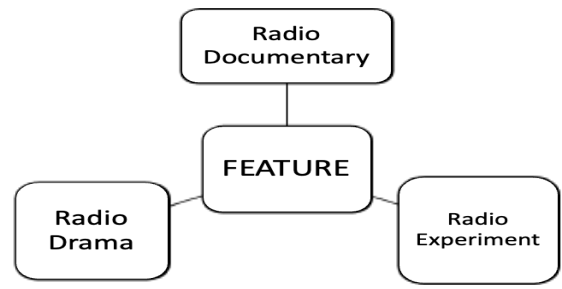

\section{Table 3.}

Planetary understanding of artistic radio genres with broadcast examples. Own elaboration.

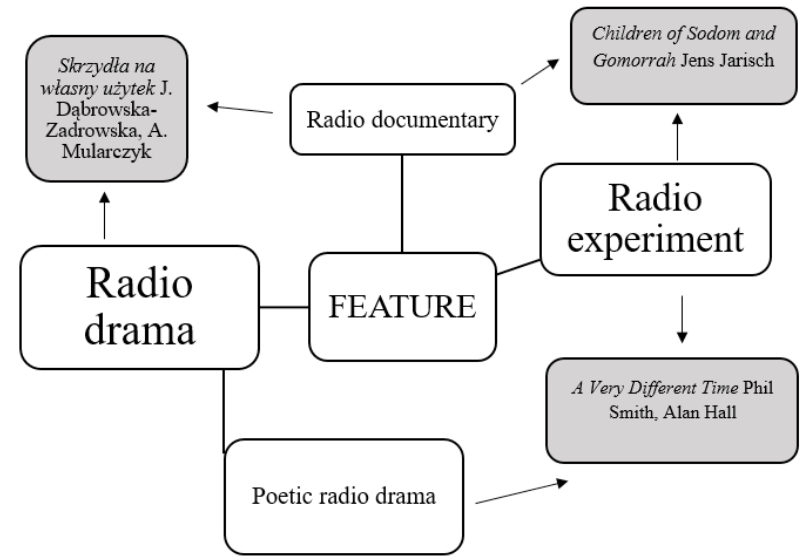


Documentary radio drama as Marchwicki by Michał Turowski could be another link in the system between radio drama and radio documentary. Another way to extend the system has to do with the genre's varieties as poetic radio documentary like White Contains All Other Colours by Shenja von Mannstein. Poetic radio documentary is not a straight connection between two artistic radio genres but that is the strength of this system that can be developed in every possible direction without any limitations. Only this kind of understanding of artistic radio genres can reflect their diversity typical for any kind of art.

In the description of the research methodology necessary for the analysis of journalistic genres Maria Wojtak (2004) detailed four aspects of the genre pattern: structural aspect, pragmatic aspect, cognitive aspect and aspect of style. In reference to feature, I understand those components as follows:

1. The structural aspect is connected with a composition of a work, with particular scenes, structural elements and certain - natural and created - voice materials present in the work. It is the whole program, appropriately composed by the author, where all the elements influence each other and constitute the final overtone of the work. The composition of the feature is naturally different in individual realizations and it may resemble the format of other radio genres. Essential in this aspect are artistic values, which I perceive as the author's overriding aim, that their program is a work of art and has aesthetic values. In the feature's implementation, aesthetic acoustic solutions are not always directly related to the category of beauty and harmony of reception, sounds frequently used will be unpleasant for the listener, but these will be the way to the intended artistic effect. For instance, experimental forms do not reject antiaesthetic practices, the creators decide to induce in the recipient "aesthetic disapproval as a component of the artistic effect" (Mukařovský, 1970, p. 77).

2. The pragmatic aspect refers to the purpose of the message, the situation of the recipient and the sender and the illocution potential. This aspect is related to the producer's artistic intention or the desire to tell the story as the primary goal of the broadcast. All features discuss a certain slice of reality and are the programs with a documentary component, but the proportions between real history and artistic message may be different for individual projects, which affects the goal that the author wanted to achieve.

3. The cognitive aspect is understood as the subject of the program and the manner of its presentation, which in artistic and documentary works will be related to documentary elements, presenting a given piece of reality, the true story that the author wants to tell. Regardless of fact that the feaure's example is perceived as artistic or experimental, feature will always convey some truth about the world: a specific character, event, phenomenon or author's own story. 
4. The style aspect is related to the sounds used in the work: voice materials, acoustic kitchen, music, conscious use of silence, abstractive and natural sounds. These components are extremely important in works as feature, where form is as important as content. Feature uses all audible means; programs are purely artistic realizations.

Such an understanding of particular aspects gives a complete picture of the genre pattern of the feature, but it is important to remember facts about its variation. As Wojtak stated "I do not treat the genre pattern as a permanent (constant) quality or a measure of the degree of perfection of individual representations" (Wojtak, 2004, p. 18). Particular exemplifications of the genre may take the form similar to radio play, radio documentary or radio experiment, but it is impossible to measure their value and closeness to perfection - for example by the amount of voice materials or artistic means.

\section{The contemporary feature and its subgenres}

The composition of an artistic radio work, regardless of genre, consists of content and form, but it is equally important in the feature. The form of the work consists of all elements that help to present the story and are the artistic value scale of the work. This includes editing, the way the program is composed along with all editing activities: transitions between scenes, acoustic kitchen that is the equivalent of visuality, additional acoustic effects that are not necessarily associated with visualizing sounds, but are designed to make the work more interesting. Producers can also provide sound metaphors, which is a kind of audio procedure in which the author - by using it in the right context or with some repetition - gives the sound a meaning it originally did not have.

Such treatments - in high intensity - known mainly from experimental realizations, are used, for example, by Gregory Whitehead in the compilation of Disorder Speech, records compilation from 1984-85. Whitehead deforms the voice recording of the sentence If a voice like, then what? and experiments with manual editing of tapes (Eva, can I stab bats in the cave?). These elements are as important as the words in the recordings and should be analyzed as one whole.

I understand the composition and structure of the work as a system of individual scenes and sounds in the feature. In artistic radio works the arrangement of events often differs from the way of presenting content in radio reports. The listener is not always informed about the staging of the work (Dreaming of fat men by Lorelei Harris), the story can be combined with the author's dream description (Sky Boy by Hana Walker-Brown), the show may contain fragments of the real story, but it will not be a key element of the message (Gregory Whitehead's Lovely Ways to Burn) or the main character does not appear in the 
work, the story is presented by the author and actress based on protocols (On the Shore Dimly Seen by Gregory Whitehead).

Analysing the components of documentaries and fictional characteristics in contemporary radio productions and the ways of applying both of them, I distinguished eight types of modern feature: staged, author's narration, direct narrative, with elements of drama, acted, hero-author, mosaic and experimental (Kowalska, 2019).

Table 4.

Feature's subgenres. Own elaboration.

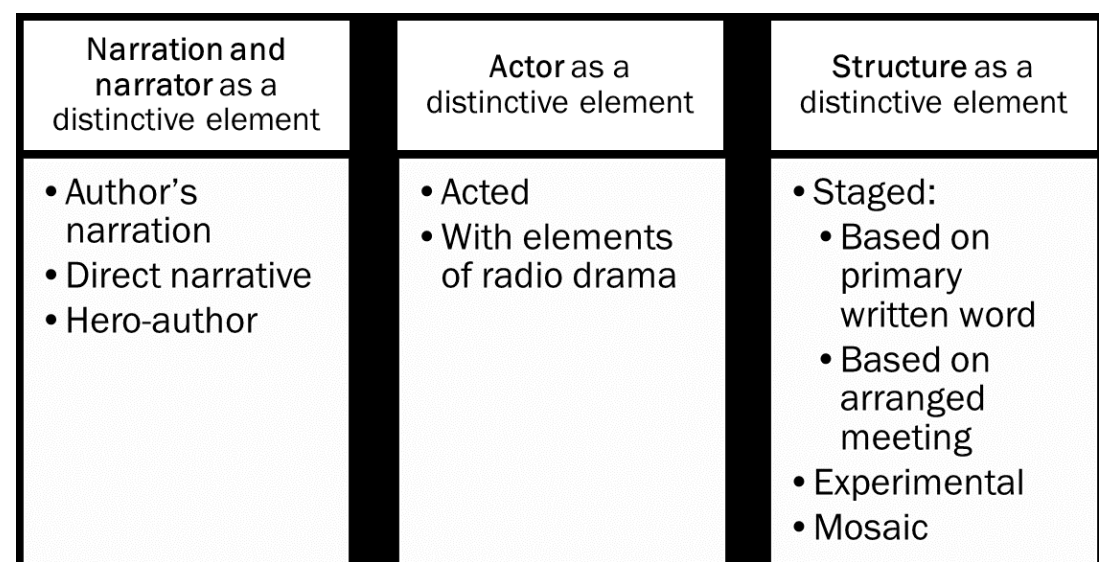

The author's narrative feature is one of the more popular forms. In works of this kind there appear the author's narration parts. The reporter can comment on the situation, add things, locate the action. The narrative parts are not spoken spontaneously, but prepared well in advance by the author. This type of process is used by Katarzyna Michalak, among others, in the programmes Mijajac Ewe (Passing Eve) and Jakiś Inny (Some others), as well as by the British creator of radio documentaries, Hana Walker-Brown, in her radio show Bluebelle: The Last Voyage.

Creators introducing narration to their works sometimes decide to use direct narration - direct narrative feature. In this type of work there are also preprepared narrative parts, however, they are spoken by the protagonists of the work, not by their author. These are elements associated with the re-spoken word. In the program My Lobotomy, dedicated by David Isay to Howard Dully, who as a young boy underwent surgical lobotomy, it is as if the listener is carried along Dully's journey by the narrated parts, the program consists of narrative statements giving rhythm to the entire story, as well as Dully's spontaneous conversations with other patients, their families and the son of the doctor who carried out the treatment. 
Another example of this kind of work is Man at the Beer Café by Susanne Björkman. The author made her feature at the bar where a man was spending his time alone. The protagonist opens himself in front of the reporter and confides during the recording. The recording was not planned, the author was not scheduled at the 'Beer Cafe' in Malmö with her interlocutor, but their unexpected meeting resulted in an interesting program. The unusual design of the feature consists in the fact that despite the spontaneous meeting, the man's monologue bears the hallmarks of a direct narration.

In his first words, the hero says: "You are a lonely man. You have few friends. And those you have... you cannot be in touch with them, it's impossible, that's the truth [...]. You have to run away somewhere, you have to go out, you cannot always sit in the room and stare. You don't know where you should go". The remark to the addressee and a coherent narrative of the statements do not resemble spontaneous conversation. What is more, the program does not tell a specific story, the plot does not aim at the climax, it is rather a self-portrait of a lonely man. After fragments formulated in the second person, the protagonist begins to express himself in the first person and he says: "I go to the beer cafe, the people who sit there are probably half-drunk, some probably more. But still... I have nowhere to go. I don't have to step in between them, but I sit down with a pint of beer and drink. I am reading a newspaper. Or something like that". First-person statements combine with those formulated in the second person, the man continues: "When you sit there for quite a while, you cannot afford a drink anymore. You know, it's quite expensive. Then stroll back home, at least something happened today. Yeah...". The narrative statements of the protagonist fulfill the phatic function of narration in the work, as the only voice material undoubtedly also has an aesthetic role.

Creativity in radio programs with a documentary nature may also appear in the form of staged situations. Radio documentary in its classic form does not allow elements of fictional or "artificially" created situations; everything the reporter records should happen naturally. But producers often decide to create the situation or base the whole story on diaries or letters. Lorelei Harris, Irish author of artistic radio documentary, created two features that show the way feature can be staged.

The feature Dreaming of Fat Men was produced for the Irish station RTÉ Radio 1 in 1995 and was awarded with perhaps the most important radio award - the Prix Italia; its author is considered to be one of the most significant, important artists in the world of radio. Dreaming of Fat Men is a radio program with an interesting form - an audio recording of the feast of four women was supplemented by their statements directly into the microphone. The meeting of the protagonists was arranged by the author, and for the duration of the feast the radio studio was transformed into a restaurant rich in gourmet food. It is 
the arranging of this meeting - and thus its staging, creating a situation - that makes the work qualify as an example of the genre in question. The women who were the heroines of the program would not have met spontaneously, would not have sat down to dinner together, if it had not been for Harris inviting them to the studio.

Another piece of Harris's I would like to mention is Love Letters from the Front. This program tells the love story of an English soldier and an Irish woman. Eric, shortly after their meeting each other, was sent to the front, from where he wrote letters to Phyllis. They exchanged about 200 letters from 1914 to 1916, when Eric died of his injuries. The correspondence was found in a British Library and became the basis of the show. The letters are read by actors incarnating the roles of Phyllis and Eric, and the lines are therefore authentic, this story really happened, but was restored by using theatrical methods. Given the fact that the letters were not altered by the creator of the broadcast, their content was not rewritten in the form of a script, the whole program has a documentary character, not theatrical.

Both programmes discussed so far were therefore staged, the first, in the form of a created situation, while the other, entirely in textual narrative, previously written down, but not spontaneously spoken into the microphone, as in the case of a radio documentary.

The feature is sometimes enriched, as I have already pointed out in the introduction, by elements of drama (feature with elements of drama): such items appear in the radio documentaries Modlitwa Zapomnianej (Forgotten Prayer) and Ztoty Chtopak (Golden Boy) by Katarzyna Michalak. In the latter, the drama happens at the beginning, where there is a short dramatized scene carrying the listener into the world of the work's main protagonist, Abraham Tuszyński. The story begins with a dialogue between two actors, for whom the action takes place in the 1920s, a period in which Abraham Tuszyński founded a famous cinema:

Woman: Hey, why are you not looking at the screen?

Man: Just look at their faces.

Woman: Whose?

Man: The spectators. They look completely different than in the daylight.

No one is tired, anxious, angry ...

Woman: Well they're in the cinema.

Man: Yes, in the cinema. Only in the cinema are dreams fulfilled.

The author uses radio drama to give a voice to the main character of the story. A similar situation occurs in a documentary telling the story of Tekla Bądarzewskiej-Baranowska, Modlitwa Zapomnianej (Forgotten Prayer): 
in dramatized scenes carrying the listener to hero's contemporary times, the obituary of the artist is read, a scene is also acted out where the young composer the composer asks for an opinion on her works.

These elements enrich the message, so it has a greater influence on the imagination of the listener. Naturally important and interesting for the audience was also the appearance of the protagonists of the documentaries. Both works are about people born in the nineteenth century, so the use of voice actors was the only option.

An actor can also appear in the role of one of the protagonists, which can be called an acted feature. In this variation of the feature, the protagonist is played by an actor, and a common reason for the use of this form is the making of programs about people who are dead, which was the case with Black Roses: The Killing of Sophie Lancaster by Susan Roberts.

The actor playing the protagonist can also appear in the role of the hero in the drama scenes. Is it an acted feature or maybe feature with elements of radio drama with extended monologues? This double-role was present in Zygmunt Jabłoński's Great Network produced in Polish Radio in 1961. The distinction between varieties in this case will be based on the rule of unity of time and place of action. Monologues may be an extension of the stage or a separate voice material. Thematic separateness between monologues and drama scenes creates the mosaic composition of the work as it took place in Great Network.

The author is usually a reporter, a producer of audio works. However, it can happen that some or all of the recordings are made by the protagonist. In the protagonist-author feature there are recordings that have been made by the protagonist of the work. The impetus for their creation may be the desire to preserve certain situations, conversations or the need to create audio letters. Letters to Butchie is a radio show in which audio letters are recorded by a mother, Jeannie Reilly, to her son, though the author of the broadcast is David Isay. The impetus for the recording of certain situations or words may be to transfer them to another person. This was the case with Jeannie Reilly, the protagonist of Letters to Butchie, a woman who abandoned her child, and the recordings - as its title suggests - were audio letters from a mother to her son.

The hero-author features are perhaps the most intimate kind of message. Recordings can be made completely without the participation of a reporter, whose role in this case is to select recordings and arrange them from the right composition. The radio producer can also provide the hero with temporary recording equipment and only some part of the recordings will be made by the protagonist. Another way to produce this subgenre of feature is to create a program about the reporters themselves. An example of this type of work is The 
Ground We Lived On by Adrian Nicole LeBlanc and Sarah Kramer, where the protagonist and the author of the recordings is Adrian Nicole LeBlanc.

The creators of features including several types of fiction in a mosaic feature. In contrast to the works referred to as experimental, the fabrications or fictional elements do not dominate the program, rather they complete it. The mosaic feature is a syncretic subgenre of feature. This kind of work combines several types of varieties, which I discussed in the previous parts of this article. Artistically advanced productions often use several types of creation, the most common element appearing in this type of work is the author's narrative combined with other forms of fiction.

A work of this type is Dada à gogo by Maidon Bader. The author, in addition to a coherent story, conveys to the listener the possibilities offered by a radio feature: non-standard montage, the introduction of an actor and the repetition of certain issues. All the methods used by her are intended as reflections on the theme of the works of Dadaism.

A contemporary example of a work with an experimental nature may be Lovely Ways to Burn produced by Gregory Whitehead in 1990 for New American Radio. It is a 'documentary hybrid' (DP, 2012), in which three stories are told: a story based on a scenario of electroconvulsive therapy, an interview with a girl who has been burned and comments on the phenomenology of fire. The narrative is non-linear; the stories are not told chronologically. On a number of occasions, you can hear the song Fever. Throughout the duration of the song you can hear the troubling sounds of electric shocks.

The whole narrative seems to be inconsistent, non-linear, the statement of a man on the medical use of electroshock treatment is suddenly interrupted by a few second-long recordings during which you can hear the sounds of an electric shock and muffled cries, but Lovely Ways to Burn also tells a story. The stories are not told in a simple, logical way, but still you can tell what the work involves. The memories of the girl are - necessary in a documentary - a real element, and the story about electroshock treatment was unfolded on the basis of a script. The third component of the programme, concerning the phenomenology of fire, is an artistic and metaphorical supplement.

I view Whitehead's work as the 'final' form of this genre. In search of the limits of the genre, I could find no programme that would have even greater artistic and aesthetic value while maintaining a connection with reality, and thus - with documentary.

\section{Conclusion}

On the basis of Polish radio studies and radio journalism, the term feature is becoming more recognizable and more often used. The concept of artistic 
documentary is still also applied interchangeably. Polish definitions of the genre refer to the presence of fictitious elements, while British and American researchers analysing and defining the genre seem to emphasize the creative intentions of the reporter and the innovative form of programmes. The dual definition makes it difficult to classify the genre of individual programmes.

The planetary understanding of artistic radio genres proposed by me in the first part of the article is the result of feature's variety. In all these forms we have to to use this paradoxical statement - deal with fiction in the service of truth. Truth means full authenticity and faithful reflection of reality. However, especially in the context of art, it often becomes a pretext for the author to tell a story or describe their emotions, without extreme mimicry and overarching purpose in the form of reporting a certain phenomenon.

The feature as a genre is internally very diverse. Within it there are programmes with a significant share of fiction, or those almost identical to a radio documentary, experimental forms, and forms which lie on the boundaries. Since in this type of programme form is as important as content, the individual creator of the work becomes crucial, giving shape to a true story.

The way in which the elements of fiction, both created and staged, are applied to a work based on a real story, is a matter for individual radio creators. The feature, located between documentary, experiment and radio drama, can approach the form of those three genres; the proportions between the elements which are non-fictional, imagined or staged are individual to every work.

The fictitious components that are the basis of feature's categories discussed in the paper, are a formal representation of the artist's artistic composition. The essence of the feature is the synthesis of the documentary truth, the perspective of the author and their creative expression. Reality becomes the starting point for creating an artistic programme where form and content are inseparably connected. The facts triggered the imagination and become the material to create the story. Artistic segments created by the author are no less important or disturbing documentary messages, they are an inherent part of the feature and can also convey the truth.

\section{References:}

Andersch, A. (1953). Versuch über des Features, 'Fehrsehen und Rundfunk', no. 1.

Bader, M. (Writer). (n.d.) Dada à gogo [Radio].

Björkman, S. (Writer). (n.d.) Man at the Beer Café [Radio].

Chatterjee, M. (n.d.). Radio Documentary: Slice of Life Through Sound and Silence. Retrieved July 10, 2021 from https://www.angelfire.com/nd/nirmaldasan/ journalismonline/rd.html. 
DP. (2012, August 04). Lovely ways to burn. Retrieved March 13, 2021, from http:// gregorywhitehead.net/2012/07/29/lovely-ways-to-burn/.

Gilliam, L. (1950). BBC Features, London: Evans Brother Limited.

Harris, L. (Writer). (n.d.) Dreaming of fat men [Radio].

Harris, L. (Writer). (n.d.) Love Letters from the Front [Radio].

Isay, D. (Writer). (n.d.) Letters to Butchie [Radio].

Isay, D. (Writer). (n.d.) My Lobotomy [Radio].

Jabłoński, Z. (Writer). (n.d.) Great Network [Radio].

Jarisch, J. Was ist eigentlich ein Feature? Retrieved October 4, 2014 from http://www. yeya.de/journal/faq.

Kąkolewski, K. (1987). Wańkowicz krzepi. Wywiad-rzeka, Lublin: Lubelskie Publishing.

Klimczak, K., (2011). Reportaże radiowe o krzywdzie i cierpieniu. Łódź: Primum Verbum.

Kowalska, N. (2019). Forma i treść. Polski i zagraniczny feature radiowy oraz jego odmiany gatunkowe. Łódź: University of Lodz Publishing.

LeBlanc, A. N., \& Kramer, S. (Writers). (n.d.) The Ground We Lived On [Radio].

Michalak, K. (Writer). (n.d.) Jakiś Inny (Some others) [Radio].

Michalak, K. (Writer). (n.d.) Mijając Ewę (Passing Eve) [Radio].

Michalak, K. (Writer). (n.d.) Modlitwa Zapomnianej (Forgotten Prayer) [Radio].

Michalak, K. (Writer). (n.d.) Ztoty Chtopak (Golden Boy) [Radio].

Mukařovský, J. (1970). W'śód znaków i struktur, Warsaw: Państwowy Instytut Wydawniczy.

Roberts, S. (Writer). (n.d.) Black roses: The Killing of Sophie Lancaster [Radio].

Street, S. (2012). The poetry of radio: The colour of sound. London: Routledge.

Turowski, M. (Writer). (n.d.). Marchwicki [Radio].

von Mannstein, S. (Writer). (n.d.) White Contains All Other Colours [Radio].

Walker-Brown, H. (Writer). (n.d.) Bluebelle: The Last Voyage [Radio].

Walker-Brown, H. (Writer). (n.d.) Sky Boy [Radio].

Whitehead, G. (Writer). (n.d.) Disorder Speech [Radio].

Whitehead, G. (Writer). (n.d.) Lovely Ways to Burn [Radio].

Whitehead, G. (Writer). (n.d.) On the Shore Dimly Seen [Radio].

Wojtak, M. (2004). Press journalism genres. Lublin: Maria Curie-Skłodowska University Publishing. 